\title{
EDITORIAL
}

\section{Pitfalls in accurate estimation of overdiagnosis: implications for screening policy and compliance}

\author{
Stephen A Feig* \\ See related research by Duffy and Parmar, http://breast-cancer-research.com/content/15/3/R41
}

\begin{abstract}
Stories in the public media that 30 to $50 \%$ of screendetected breast cancers are overdiagnosed dissuade women from being screened because overdiagnosed cancers would never result in death if undetected yet do result in unnecessary treatment. However, such concerns are unwarranted because the frequency of overdiagnosis, when properly calculated, is only 0 to $5 \%$. In the previous issue of Breast Cancer Research, Duffy and Parmar report that accurate estimation of the rate of overdiagnosis recognizes the effect of lead time on detection rates and the consequent requirement for an adequate number of years of follow-up. These indispensable elements were absent from highly publicized studies that overestimated the frequency of overdiagnosis.
\end{abstract}

\section{Introduction}

Overdiagnosis refers to the possibility that some cancers detected at screening would not be symptomatically detected before the patient died from some other cause. Supposedly, such cancers may be slow growing, have a low likelihood of metastasis or be found in older women whose co-morbid conditions limit any meaningful tumor progression during their lifetime. Such women might be subjected to potential harms including unnecessary lumpectomy or mastectomy, radiation therapy and chemotherapy, anxiety from knowledge of their cancer and medical care costs for them and for society at large.

The extent of overdiagnosis has been estimated from the difference between the observed incidence of cancer following screening and the expected incidence in the absence of screening. Because screening detects cancer

\footnotetext{
*Correspondence: sfeig@uci.edu
}

Department of Radiological Sciences, UCI Medical Center, University of California Irvine School of Medicine, 101 City Drive South, Route 140, Orange, CA 928683298, USA sooner than it would present clinically, however, detection rates at screening are higher than incidence rates in the absence of screening, especially during the first several years after screening begins. A sufficiently long follow-up time and adjustment for the detection lead time are thus necessary for accurate estimation.

\section{Need for sufficiently long follow-up}

The study by Duffy and Parmar represents a major advance because it calculates the length of follow-up time necessary to preclude any overestimation of overdiagnosis [1]. According to the authors, the excess of cancers in their hypothetical screening population only falls below $10 \%$ after 25 years or more of follow-up. For the excess to be nullified or almost nullified, 30 years of follow-up are needed including up to 10 years above the upper age limit for screening. The authors elegantly explain why so many estimates have been erroneously high due to insufficient follow-up.

\section{How did length of follow-up affect prior estimates?}

To make this point, Duffy and Parmar apply their criteria to estimates made by other investigators. For example, Kalager and colleagues estimated an overdiagnosis rate of $18 \%$ at 10 -year follow-up of the Norwegian screening program [2]. However, Duffy and Parmar indicate that a $19 \%$ excess cancer rate would be expected from the lead time alone [1]. The UK Screening Trials Review Group estimated an overdiagnosis rate of 10 to $20 \%$ [3], but follow-up at two of the three UK trials extended for only 6 years beyond the end of the screening rather than at least 10 years as recommended [1].

How did adjustment for lead times affect estimates? In 2012, Puliti and colleagues reviewed 13 primary study reports with 16 estimates of overdiagnosis in seven European countries [4]. Estimates among the 10 studies lacking adjustment for lead time bias and risk were mostly in the 30 to $54 \%$ range. Adjusted estimates in the remaining six studies were $2.8 \%$ in the Netherlands, $4.6 \%$ and $1.0 \%$ in Italy, $7 \%$ in Denmark, $10 \%$ in England, and 3.3\% Wales. These results suggest that the most plausible 
estimates for overdiagnosis range from 1 to $10 \%$. The study by Duffy and Parmar builds on the prior studies by determining the length of follow-up needed to ensure a reliable estimate.

\section{Value of 29-year follow-up in the Swedish Two County Trial}

The strongest evidence that overdiagnosis is a clinically marginal phenomenon can be found in a 29-year followup of one arm of the Swedish Two County Trial, where the cumulative incidences of breast cancer (invasive and in situ combined) in the study group offered screening between ages 40 and 74 and in the control group were virtually identical [5]. There was only a nonsignificant excess among those aged 70 to 74 at randomization. This study suggests that the level of overdiagnosis is small and largely confined to the initial (prevalence) screen or perhaps to older women.

\section{Weaknesses of estimates based on national trends rather than on screening data}

In contrast to estimates for overdiagnosis made on the basis of screening studies, those estimates based on the changes in incidence rates are unreliable. For example, Bleyer and Welch compared US National Cancer Registry data during 1976 to 1978 (where little screening occurred) with data for the years 2006 to 2008 when 60\% of women aged 40 and older were being screened [6]. They found that the incidence of invasive breast cancer during 2006 to 2008,128 per 100,000 , was $31 \%$ higher than extrapolated from their estimated $0.25 \%$ per year increase from their 1976 to 1978 baseline data. They ignore the fact that the increase over the much longer 40-year prescreening period (1940 to 1980) was actually $1 \%$ per year [7]. As noted by Kopans, a rate of 128 per 100,000 is actually lower than the 132 per 100,000 women expected based on a continued increase of $1 \%$ per year [8].

Unfortunately, their conclusion that $31 \%$ of breast cancers are overdiagnosed was uncritically accepted by the news media, including a front-page article in the New York Times Magazine [9]. This episode illustrates why estimates for overdiagnosis based on national trend data involve tenuous assumptions and are fraught with dangers. Healthcare planners may then use such incorrect conclusions to justify changes in screening guidelines. Women may also be dissuaded from being screened.

\section{Ductal carcinoma in situ}

One limitation of the study by Duffy and Parmar is that their method pertains to invasive cancers only and not to the potential overdiagnosis of ductal carcinoma in situ. However, other studies suggest that most cases of DCIS are capable of becomining invasive disease [4, 5,10-13]. Hopefully, further progress in molecular markers will allow better distinction and appropriate treatment for different types of ductal carcinoma in situ [14]. In the interim, many studies suggest that most ductal carcinoma in situ is a potentially invasive disease [12].

\section{Competing interests}

The author declares that he has no competing interests.

Published: 8 August 2013

\section{References}

1. Duffy SW, Parmar D: Overdiagnosis in breast cancer screening: the importance of length of observation period and lead time. Breast Cancer Res 2013, 15:R41.

2. Kalager M, Adami H, Bretthauer M, Tamimi R: Overdiagnosis of invasive breast cancer due to mammography screening: results from the Norwegian screening program. Ann Intern Med 2010, 156:491-499.

3. Independent UK Panel on Breast Cancer Screening: The benefits and harms of breast cancer screening: an independent review. The Lancet 2012, 380:1778-1786.

4. Puliti D, Duffy SW, Miccinesi, G, de Koning H, Lynge E, Zappa M, Paci E; EUROSCREEN Working Group: Overdiagnosis in mammographic screening for breast cancer in Europe: a literature review. J Med Screen 2012, 19(Suppl 1):42-56.

5. Yen A M-F, Duffy SW, Chen TH, Chen LS, Chiu SY, Fann JC, Wu WY, Su CW, Smith RA, Tabár L: Long-term incidence of breast cancer by trial arm in one county of the Swedish Two County Trial of Mammograpy screening. Cancer 2012, 118:5728-5732.

6. Bleyer A, Welch HG: Effect of three decades of screening mammography on breast cancer incidence. N Eng/ J Med 2012, 367:1998-2005.

7. Garfinkel L, Boring CC, Heath CW Jr: Changing trends: an overview of breast cancer incidence and mortality. Cancer 1994, 79(Suppl):222-227.

8. Kopans DB: The New England Journal of Medicine article suggesting overdiagnosis from mammography screening is scientifically incorrect and should be withdrawn. J Am Coll Radiol 2013, 10:317-319.

9. Orenstein P: The problem with pink: our feel-good war on breast cancer. New York Times Magazine; 25 April 2013:36-43,66-69.

10. McCann J, Treasure P, Duffy S: Modelling the impact of detecting and treating carcinoma in situ in a breast cancer screening programme. J Med Screen 2004, 11:117-125.

11. Yen MF, Tabar L, Vitak B, Smith RA, Chen H-H, Duffy SW: Quantifying the potential problem of overdiagnosis of ductal carcinoma in situ in breast cancer screening. Eur J Cancer 2003, 39:1746-1754.

12. Feig SA: Ductal carcinoma in situ: implications for screening mammography. Radiol Clin North Am 2000, 38:653-669.

13. Silverstein MJ, Poller DN, Waisman JR, Colburn WJ, Barth A, Gierson ED, Lewinsky B, Gamagami P, Slamon DJ: Prognostic classification of breast ductal carcinoma-in-situ. Lancet 1995, 345:1154-1157.

14. Masood S: Focusing on cancer overdiagnosis and overtreatment: the promise of molecular medicine. Breast J 2012, 19:127-129.

doi:10.1186/bcr3448

Cite this article as: Feig SA: Pitfalls in accurate estimation of overdiagnosis: implications for screening policy and compliance. Breast Cancer Research 2013, 15:105 